\title{
O USO DO MODELO VAR NA DETERMINAÇÃO DO PREÇO DE BOVINOS VIVOS NO PERÍODO DE 1995-2014
}

\author{
Mateus Boldrine Abrita ${ }^{1}$ \\ Allan Silveira dos Santos ${ }^{2}$ \\ Gercina Gonçalves da Silva ${ }^{3}$
}

\begin{abstract}
RESUMO
O mercado da carne é de grande importância para a economia brasileira. Desse modo, o objetivo do trabalho é analisar como os rendimentos reais dos trabalhadores assalariados, as exportações e o abate de vacas interferem no preço da arroba do boi gordo no Brasil no período de 1995 até 2014, para tal, foi utilizada a metodologia dos modelos autoregressivos VAR. A hipótese do estudo é a de que a quantidade de vacas abatidas nos períodos anteriores ao de análise, também é uma fonte importante para determinar os preços no período atual. Essa variável deve ser defasada, pois, se ocorrer uma elevação no abate de vacas hoje e essas deixarem de produzir bezerros, o impacto no mercado se dará alguns anos à frente. Os resultados indicam que todas as variáveis impactam o preço da arroba do boi gordo de acordo com a lógica econômica. As exportações e os rendimentos impactam positivamente os preços, já o abate de fêmeas, impacta negativamente no curto prazo e positivamente no médio prazo.
\end{abstract}

Palavras-chave: mercado de carnes, modelo VAR, preço do boi gordo.

\section{THE USE OF VAR MODEL IN DETERMINING THE PRICE OF LIVE CATTLE IN THE PERIOD OF 1995-2014}

\begin{abstract}
The meat market is of great importance to the Brazilian economy. Thus, the objective is to analyze how the GDP, workers' in comes, exports and slaughter of cows interfere with arroba price of cattle in Brazil from 1995 until 2014, for such a methodology of models was used auto regression VAR. The study hypothesis is that the number of cows slaughtered in periods prior to analysis, is also an important source for determining prices in the current period. This variable should be lagged, as arise in the slaughter of cows occurs today and these fail to produce calves the

${ }^{1}$ Graduação em Ciências Econômicas (UFMS). Mestrado em Ciências Econômicas (UEM). Doutorando em Economia (UFRGS). Professor efetivo da Universidade Estadual de Mato Grosso do Sul. E-mail: mateusabrita@hotmail.com

${ }^{2}$ Graduação em Economia na Universidade Federal de Sergipe - UFS. Mestrado em Economia na Universidade Estadual de Maringá - UEM. Doutorando em Economia na Universidade de Brasília - UnB. Email: allansilveira1@gmail.com

${ }^{3}$ Graduação em Ciências Econômicas (UFMS). Mestrado em Administração - Linha de Pesquisa: Agronegócio - (UFMS). Doutoranda em Ciências Ambientais e Sustentabilidade Agropecuária - Linha de Pesquisa: Agronegócio e produção sustentável - (UCDB). E-mail: gercina.goncalves@gmail.com
\end{abstract}


market impact will be a few years a head, when the calf was at the point of slaughter. The results indicate that all variables impact arroba of cattle according to economic logic of the system. GDP, exports and positively impact revenue, since the slaughter of females has a negative impact in the shorttermand positively in the medium term.

Keywords: meat market, price of live cattle, VAR Model.

\section{INTRODUÇÃO}

O mercado de carne bovina tem se mostrado em evolução nos últimos anos no Brasil. Um dos reflexos dessa evolução pode ser percebido na importância do Brasil no comércio mundial de commodities. O país é o maior exportador de carne bovina no mundo ${ }^{4}$, assim como o segundo maior produtor, atrás apenas dos EUA.

Choques cambiais, o aumento ou decréscimo das exportações, o aumento do consumo mundial dos nossos parceiros comerciais, variação nos custos dos insumos e dos estoques, aumento da renda e do mercado interno, são exemplos de variáveis que podem interferir na determinação dos preços dessa commodity.

Os fatores acima mencionados, a dificuldade de se ajustar rapidamente a oferta aos preços, em virtude do tempo gasto na engorda do animal, dentre outros choques sobre os preços fazem com que o preço da carne bovina tenha uma oscilação natural.

Em virtude de tais oscilações, quando há uma determinada relação de preços, muitas vezes o produtor opta por abater mais vacas, dado que o ciclo de término da fêmea (período em que fica pronta para o abate) é mais rápido do que do boi gordo. Portanto, quando se intensifica o abate de futuras matrizes pode ocorrer à diminuição da oferta de bezerros nos períodos subsequentes, o que leva a redução do tamanho do rebanho, mesmo que de modo marginal.

Desse modo, o presente trabalho tem como objetivo analisar as relações entre as variáveis Exportações, rendimento real dos trabalhadores assalariados e abate de fêmeas e verificar o quanto estas variáveis podem explicar o preço da arroba do boi gordo. A inovação do estudo está na hipótese que será aqui testada, a qual consiste em observar se a quantidade de vacas abatidas nos períodos anteriores ao de análise, também é uma fonte importante para determinar os preços no período atual. Essa variável deve ser defasada, pois se ocorrer uma elevação no abate de vacas hoje e essas deixarem de produzir bezerros o impacto no mercado só se dará alguns anos à frente, quando o bezerro estaria no ponto de abate.

A fim de testar a validade desta hipótese, o presente trabalho, além desta breve introdução, possui mais quatro seções. Na seção a seguir, será apresentado um levantamento bibliográfico acerca do tema, posteriormente será apresentada a metodologia do trabalho. Após esse, são descritas as variáveis do modelo e são realizados os testes de robustez. No tópico seguinte, são apresentados os resultados da estimação, e por fim, são apresentadas as considerações finais do trabalho.

\section{O MERCADO DA CARNE BOVINA}

No ano de 2013 a população mundial atingiu o número de 7,2 bilhões de pessoas. De acordo com as projeções de crescimento demográfico, apresentadas

${ }^{4}$ Fonte: USDA - abr/2013. 
pela ONU, a população global deve chegar a 8,1 bilhões de pessoas em 2025 e a 9,6 bilhões, em 2050 (SACHS, 2008).

A tendência mundial do aumento populacional, o aumento na taxa de urbanização, mais as projeções de aumento da renda podem determinar mudanças na demanda por carne, considerando suas características no que tange a elasticidade-renda, significando que um incremento na renda deve incrementar a demanda por carnes principalmente para as classes sociais de menor renda (BRANDÃO, 2013). Somado a esse movimento, a renda de algumas regiões do globo se elevaram na última década o que propiciou uma maior demanda pelo produto, mesmo que ainda de modo marginal, isso porque, em alguns desses países existia uma demanda reprimida em relação ao consumo de carne bovina, muitos países asiáticos se enquadram nessa situação, entre eles, a China.

Destacando-se no cenário internacional, no segmento agronegócio, o Brasil tem se firmado como importante produtor e exportador de alimentos para diversos países, com destaque para a cadeia bovina (DAMBORIARENA; VIANA, 2014). Considerando especificamente a cadeia da carne bovina no Brasil, Buainain e Batalha (2007) afirmam que no contexto da economia rural do Brasil, essa ocupa uma posição de destaque, utilizando grande quantidade de terra para a produção e gerando emprego e renda para milhões de brasileiros.

De acordo com o MAPA (2014) no cenário do agronegócio brasileiro, a bovinocultura é um dos principais destaques no cenário mundial, possuindo o segundo maior rebanho efetivo do mundo, com cerca de 200 milhões de cabeças. A partir de 2004 o Brasil assumiu a liderança nas exportações, negociando um quinto da carne comercializada internacionalmente e transacionando com mais de 180 países.Conforme o IBGE (2014), no último trimestre de 2013, o abate no Brasil atingiu pela terceira vez consecutiva o recorde na série trimestral, com a marca de 8,888 milhões de cabeças abatidas. Na Tabela1, é possível verificar o incremento do rebanho em 2013, em relação ao ano de 2010.

Tabela 1 - Suprimento bovino brasileiro.

\begin{tabular}{|c|c|c|c|c|c|}
\hline & 2010 & 2011 & 2012 & $2013^{*}$ & $2014^{\star}$ \\
\hline $\begin{array}{l}\text { Rebanho } \\
\text { (milhões de cabeças) }\end{array}$ & 209, & 212,8 & 211,3 & 212,2 & 213,7 \\
\hline $\begin{array}{l}\text { Produção de carne } \\
(1.000 \text { t equiv. carcaça) }\end{array}$ & $8.782,5$ & $8.448,4$ & $8.751,7$ & $9.561,7$ & $9.752,9$ \\
\hline $\begin{array}{l}\text { Importação } \\
\text { (1.000 t equiv. carcaça) }\end{array}$ & 40,8 & 44,8 & 60,1 & 57,1 & 58,2 \\
\hline $\begin{array}{l}\text { Exportação } \\
\text { (1.000 t equiv. carcaça) }\end{array}$ & $1.701,5$ & $1.494,6$ & $1.684,4$ & $2.007,3$ & $2.067,5$ \\
\hline $\begin{array}{l}\text { Disponibilidade interna } \\
\text { (1.000 t equiv. carcaça) }\end{array}$ & $7.121,8$ & $6.998,6$ & $7.127,4$ & $7.611,5$ & $7.743,6$ \\
\hline
\end{tabular}

Notas: 1) Rebanho. Fonte: IBGE; 2) Exportação e Importação. Fonte: SECEX; ( ${ }^{*}$ Estimativa da Conab.

De acordo com a Agrifatto (2013), o Brasil produz cerca de 9,4 milhões de toneladas de carne bovina por ano, dentre as quais $16,5 \%$ são negociados. $\mathrm{Na}$ última década, o Brasil apresentou um crescimento de $400 \%$ no valor de suas exportações, atingindo o recorde histórico de US\$ 5,7 bilhões em faturamento e consolidando a posição de maior exportador mundial de carne bovina.

O aumento dos índices de produção da carne bovina no Brasil tem como um dos principais contribuintes o aumento das exportações de carne. Para o IBGE (2014) o desempenho das exportações brasileiras de carne bovina in natura no 4ำ trimestre de 2013 foi superior ao obtido no trimestre imediatamente anterior e ao do mesmo período de 2012, tanto em volume quanto em faturamento. 
De acordo com o MAPA (2014), a venda de produtos do agronegócio brasileiro ao exterior apresentou um saldo positivo de US\$ 5,75 bilhões (superávit) em novembro de 2013, com US $\$ 7,16$ bilhões em exportações e US $\$ 1,41$ bilhão em importações. O setor carnes, em termos de valor exportado, foi a segunda principal área em destaque, cujas vendas alcançaram US\$15,39 bilhões entre janeiro e novembro de 2013.

Para a ABIEC (2014) as exportações brasileiras de carne bovina devem bater recorde em 2014. A projeção é de um aumento de $20 \%$ para esse ano em relação a 2013. A justificativa, portanto, seria o aumento da demanda externa e a abertura de novos mercados. Entre os principais destinos da carne bovina brasileira destacam-se Hong Kong, Rússia e União Européia, conforme Tabela 2. Apenas para a carne in natura, o faturamento totalizou US\$2,3 bilhões e o volume exportado foi de 523,6 mil toneladas (AGRIFATTO, 2013).

Tabela 2 - Destinos da carne bovina brasileira - totalidade dos produtos cárneos. Período: jan a Jun/2013.

\begin{tabular}{llrr}
\hline Posição & País & Faturamento U\$S (em milhões) & Toneladas \\
\hline $1^{\circ}$ & Hong Kong & 679.056 .716 & 172.823 \\
$2^{\circ}$ & Rússia & 615.758 .842 & 154.791 \\
$3^{\circ}$ & União Européia & 388.839 .504 & 59.949 \\
$4^{\circ}$ & Venezuela & 325.551 .868 & 60.808 \\
$5^{\circ}$ & Chile & 197.091 .790 & 36.437 \\
$6^{\circ}$ & Egito & 182.288 .936 & 53.889 \\
$7^{\circ}$ & Estados Unidos & 104.857 .892 & 11.568 \\
$8^{\circ}$ & Irã & 79.047 .095 & 17.068 \\
$9^{\circ}$ & Israel & 48.574 .045 & 9.797 \\
$10^{\circ}$ & Argélia & 41.649 .197 & 9.149 \\
\hline
\end{tabular}

Fonte: MDIC/Secex/ABIEC/AgriFatto

Além de principal exportador, o Brasil se destaca também como um dos principais consumidores mundiais de carne bovina como fonte de proteína animal. A produção nacional de bovinos tem o mercado interno como principal destino absorvendo cerca de $80 \%$ da produção. A demanda interna pode ser separada em dois grupos: os consumidores de baixa renda, que se preocupam com a quantidade a ser consumida, tendo o preço como restrição e os consumidores de alto poder aquisitivo, que se preocupam com a qualidade do produto (CARVALHO; ZEN, 2010).

Num contexto nacional, nos principais estados produtores, no ano de 2012 , no abate de bovinos brasileiros, bem como a produção, encontram-se distribuídos conforme Tabela 3: 
Tabela 3 - Produção e abate nos estados brasileiros no ano de 2012.

\begin{tabular}{l|r|r}
\hline Estados & Produção 2012 (cabeças) & Abates 2013 \\
\hline Mato Grosso & 28.740 .802 & 4.976 .087 \\
Minas Gerais & 23.965 .914 & 1.815 .042 \\
Goiás & 22.045 .776 & 2.547 .814 \\
Mato Grosso do Sul & 21.498 .382 & 3.762 .931 \\
Pará & 18.605 .051 & 1.636 .842 \\
Rio Grande do Sul & 14.140 .654 & 721.793 \\
Rondônia & 12.218 .437 & 2.050 .000 \\
São Paulo & 10.757 .383 & 2.849 .219 \\
Bahia & 10.250 .975 & 409.013 \\
Paraná & 9.413 .937 & 960.100 \\
\hline
\end{tabular}

Fonte: Elaborado pelos autores a partir de dados IBGE.

No Brasil a porcentagem da renda familiar gasta com alimentação, é de cerca de $17,10 \%$ da renda familiar dos brasileiros. Entre os produtos que compõe a cesta de produtos alimentícios, a carne é o que mais pesa nas despesas, conforme dados do IBGE (2013). Na seguinte seção serão abordados os aspectos metodológicos da pesquisa.

\section{METODOLOGIA}

\subsection{Séries temporais}

A classe de fenômenos cujo processo observacional e consequente quantificação numérica geram uma sequência de dados distribuídos no tempo é denominada série temporal (SOUZA, 1989). A natureza de uma série temporal e a estrutura de seu mecanismo gerador estão relacionadas com o intervalo de ocorrência das observações no tempo. Caso o levantamento das observações da série possa ser feito a qualquer momento do tempo, a série temporal é dita contínua, sendo denotada por $x(t)$ (GRANGER, 1977). Entretanto, de acordo com Granger (1977) e Nelson (1973), na maioria das séries, as observações são tomadas em intervalos de tempo discretos e equidistantes.

Uma série temporal discreta pode ser representada por $X^{T}=\left\{x_{1}, x_{2}, \ldots x_{T}\right\}$, sendo que cada observação discreta $x_{t}$ está associada a um instante de tempo distinto, existindo uma relação de dependência serial entre essas observações (SOUZA, 1989).

\subsection{Objetivo das séries temporais}

Granger (1977) coloca como objetivo inicial da análise de séries temporais a realização de inferências sobre as propriedades ou características básicas do mecanismo gerador do processo estocástico das observações da série. Assim, através da abstração de regularidades contidas nos fenômenos observáveis de uma série temporal existe a possibilidade de se construir um modelo matemático como uma representação simplificada da realidade (BARBANCHO, 1970).

Após a formulação do modelo matemático, obtido pela seleção entre as alternativas de classes de modelos identificadas como apropriadas para essa representação e subsequente estimação de seus parâmetros, é possível utilizá-lo para testar alguma hipótese ou teoria a respeito do mecanismo gerador do processo 
estocástico e realizar a previsão de valores futuros da série temporal (NELSON, 1973).

\subsection{Previsão de séries temporais}

Segundo Barbancho (1970), uma previsão é uma manifestação relativa a sucessos desconhecidos em um futuro determinado. A previsão não constitui um fim em si, mas um meio de fornecer informações e subsídios para uma consequente tomada de decisão, visando atingir determinados objetivos (MORETTIN, 1981).

Considerando um conjunto de observações de uma série temporal coletadas até $o$ instante $t$ e de um modelo que represente esses fenômenos, a previsão do valor da série no tempo $t+h$ (Figura 1) pode ser obtida.

\section{Figura 1 - Observações de uma série temporal com previsões de origem $t$ e horizonte $h$}

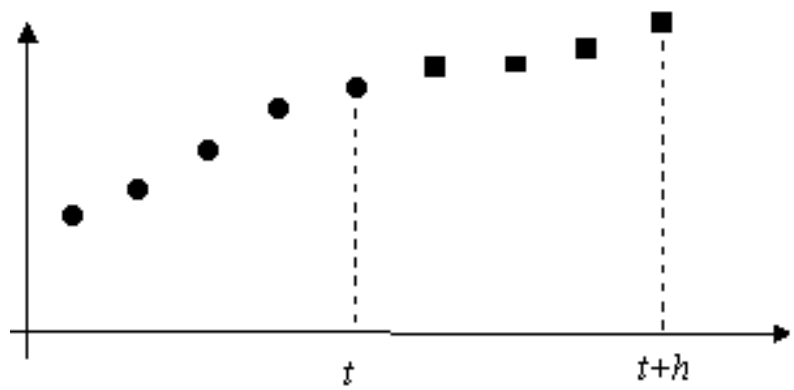

Fonte: GRANGER (1974).

Dependendo do valor assumido pelo horizonte de previsão, Souza (1989) e Wheel Wrigth (1985) classificam as previsões dos valores futuros de uma série temporal como de curto, médio ou longo prazo. Desse modo, diante da possibilidade de existência de diferentes horizontes de previsão, Refenes (1993) especifica técnicas distintas para prognosticar os valores futuros de uma série temporal:

- $\quad$ previsão múltiplos passos: esta abordagem, adotada para longos horizontes de previsão, procura identificar as tendências gerais e os pontos de inflexão mais relevantes na série temporal. Na previsão múltiplos passos, o conjunto de valores correntes é empregado na realização da previsão para determinado instante; esta previsão é, então, introduzida entre as observações passadas, compondo, desta forma, um novo conjunto de dados, sobre o qual será obtida a previsão do tempo subsequente.

- $\quad$ previsão simples passo: nesta técnica não há incorporação de previsões aos dados utilizados para encontrar a próxima previsão, sendo esta, independente dos valores anteriormente previstos. A previsão é feita apenas para o período de tempo imediatamente posterior ao atual, a partir das observações da série temporal. 
Para Souza (1989), a garantia da otimalidade das previsões de uma série temporal somente é alcançada adotando como horizonte de previsão o instante de tempo imediatamente subsequente à origem $t$.Naturalmente, a investigação do poder preditivo do modelo especificado como o mais adequado para explicar o mecanismo gerador das observações de uma série temporal é um processo empírico de verificação, visto que são feitas comparações entre as previsões e as observações, a fim de confirmar a habilidade do modelo matemático em descrever a estrutura definida pelos dados da série temporal analisada (BARBANCHO, 1970).

\subsection{Métodos de previsão de séries temporais}

Um método de previsão é o conjunto de procedimentos usados no desenvolvimento de uma determinada previsão. Os métodos de previsão de séries temporais, classificados como métodos quantitativos, baseiam suas previsões na extrapolação de características de observações passadas e no inter-relacionamento entre essas observações, fornecendo previsões acuradas se o futuro apresentar comportamento similar ao passado (WHEELWRIGHT, 1985).

De acordo com este autor, a maioria dos métodos de previsão de séries temporais se baseia na suposição de que observações passadas contêm todas as informações sobre o padrão de comportamento da série temporal e esse padrão é recorrente no tempo. O propósito dos métodos de previsão consiste em distinguir o padrão de qualquer ruído que possa estar contido nas observações e então usar esse padrão para prever os valores futuros da série temporal. Assim, pela identificação desse componente, a previsão para períodos de tempo subsequentes ao observado pode ser desenvolvida.

Apesar de quase a totalidade dos métodos de previsão de séries temporais estar fundamentada apenas na análise das observações da série de interesse para a especificação de algum modelo que descreva essas observações, alguns procedimentos de previsão tentam explicar o comportamento de uma série temporal pela evolução dos fenômenos observacionais de outras séries. Desta forma, dependendo do número de séries temporais envolvidas na modelagem, Souza (1989) classifica os métodos de previsão em univariados, funções de transferência e multivariados.

Os métodos univariados, que compreendem a maior parte dos métodos de previsão de séries temporais, consideram somente uma única série para a realização dos prognósticos. As previsões decorrentes da aplicação de métodos univariados podem estar relacionadas apenas com as informações contidas na série histórica de interesse (métodos baseados na estatística clássica) ou também, além de incorporarem essas informações, consideram outras supostamente relevantes e que não estão contidas na série analisada (métodos baseados na estatística bayesiana).

Aquelas metodologias nas quais a série de interesse é explicada não só pelo seu passado histórico, como também por outras séries temporais nãocorrelatas entre si, são conhecidas como funções de transferência. Esta classe de métodos de previsão envolve, portanto, mais de uma série temporal, com a ressalva de que a relação de causalidade entre estas séries é perfeitamente conhecida.

Os métodos multivariados abrangem os procedimentos de previsão que associam mais de uma série temporal na efetivação de prognósticos sem, no entanto, qualquer imposição com relação à causalidade entre essas séries. Diante disso, há uma variedade enorme de métodos de previsão de séries temporais, cada qual com suas capacidades e limitações (WHEELWRIGTH, 1985). Qualquer que 
seja a classificação desses métodos é possível utilizar um número muito grande de métodos diferentes para descrever o comportamento de uma série particular. A seleção do método de previsão adequado depende de vários fatores, tais como o comportamento do fenômeno observável ou o conhecimento a priori que se tenha sobre a sua natureza e do objetivo da análise.

Souza (1989) e WheelWrigth (1985) relacionam os métodos de previsão baseados exclusivamente em uma única série histórica de dados em métodos de decomposição, métodos simples de previsão e métodos avançados de previsão de séries temporais.

\subsection{Modelos autoregressivos vetoriais var}

Vários autores de renome internacional abordaram os modelos auto regressivos vetoriais (VAR), mas Sims (1980) é assinalado como um dos pioneiros em sua utilização. A utilização do modelo VAR ganhou espaço nos estudos econômicos devido a sua capacidade de analisar múltiplas relações entre diversas variáveis, a partir de determinado conjunto de restrições de identificação. Assim, são permitidas análises de resposta do comportamento de uma variável dado um impulso em outra, sendo de grande valia para os estudos das relações entre variáveis importantes.

Enders (1995) demonstra duas importantes análises possibilitadas pelo uso do modelo VAR: a decomposição da variância e a função impulso resposta. A decomposição da variância mostra o quanto mudanças de cada variável são oriundas dela mesma, ou seja, de sua própria variância, bem como o quanto ela é explicada pela variância das demais variáveis do modelo. Por outro lado, a função impulso resposta permite observar como reagem as variáveis de um determinado sistema, dado um impulso em determinada variável em um prazo de tempo, permitindo assim, a análise das relações entre diferentes variáveis em diferentes períodos de tempo.

O modelo VAR na forma reduzida apresenta resíduos correlacionados contemporaneamente, não permitindo assim, a identificação dos efeitos exógenos independentes nas variáveis. Um modo usual de identificar restrições a respeito das relações contemporâneas dos choques é a decomposição de Cholesky. Segundo Sims (1986) essa abordagem propõe uma estrutura exatamente identificada ao modelo, quando o número de variâncias/covariâncias é igual ao numero de parâmetros estimados. Dadas as ferramentas disponibilizadas, essa metodologia permite averiguar melhor as relações existentes entre preço da arroba do boi gordo e variáveis explicativas; melhorando a compreensão acerca da problemática do trabalho.

\subsection{Dados e identificação do modelo}

Será utilizado o software Eviews para obter os resultados do modelo. Com o propósito de identificar quais são os determinantes do Preço da arroba do boi gordo no Brasil, foi adotada uma base de dados que compreende o período de janeiro de 1995 até dezembro de 2014, totalizando 240 observações; número adequado para esse tipo de análise econométrica. Em linhas gerais de acordo com o modelo proposto neste trabalho, quatro variáveis principais são apontadas como determinantes do preço da arroba no Brasil: i) O preço da arroba em períodos anteriores; ii) Exportações; ili) Rendimento real do trabalhador assalariado, ou seja, descontado o efeito dos preços; iv) Abate de vacas defasados em quatro anos. 
Para estimar o modelo foram utilizadas as seguintes variáveis, entre parênteses está o nome lançado no software ${ }^{5}$ : Arroba do boi gordo (arroba) que é o preço médio recebido pelo produtor na praça do Paraná em reais, disponibilizado pela Secretaria da Agricultura e do Abastecimento do Estado do Paraná, Departamento de Economia Rural (SEAB-PR), esta variável foi utilizada como proxy para a arrobado no Brasil, considerando que o valor absoluto não é tão relevante quanto as oscilações da variável, deste modo dada a restrição de encontrar dados nacionais foi adotada esta alternativa; Exportações (FOB) retirado do Ministério do Desenvolvimento, Indústria e Comércio Exterior, Secretaria de Comércio Exterior (exportações); Rendimento real dos assalariados (rendimento) elaborado pela Fundação Sistema Estadual de Análise de Dados, Pesquisa de Emprego e Desemprego e, por fim, a quantidade de vacas abatidas (defabate_vacas) elaborado pelo IBGE.

Como o boi gordo é um produto exportável, o nível de demanda internacional pela carne bovina brasileira também é uma variável importante na determinação do preço da commodity no mercado interno. O mercado interno brasileiro é um fator que não pode ser desconsiderado nesse tipo de análise. O aumento do rendimento do trabalhador brasileiro nos últimos anos provavelmente tem exercido alguma influência sobre tais preços. Por fim, o abate de fêmeas defasados em quatro anos também será uma variável incluída no modelo, isso porque o tamanho do rebanho influencia a disponibilidade de novos animais. A lógica é a seguinte: com o aumento do número de vacas abatidas (possíveis matrizes) espera-se que num prazo de aproximadamente quatro anos (tempo para o bezerro virar boi e ser abatido) haja uma queda na produção futura, com isso, a hipótese é de que no curto prazo essa elevação no abate de vacas faça com que o preço caia, pois a oferta de carne no mercado vai ser maior, entretanto, como o rebanho vai diminuir e num prazo mais longo, o preço tende a se elevar, dada a interação entre oferta e demanda.

Assim, o benchmark do primeiro modelo segue a seguinte sequência: exportações, rendimento e defabate_vacas. O ordenamento segue a seguinte equação:

$$
\text { arroba }=f(\text { exportações }+ \text { rendimento }+ \text { defabate_vacas })
$$

Com o propósito de analisar a estacionaridade de cada série, a seguir, serão realizados testes de raiz unitários para verificar sua possível presença diante das variáveis abordadas no modelo.

\subsection{Testes de raiz unitária}

Para verificar se as variáveis seguem uma trajetória de processo estocástico estacionário foi realizado o teste de raiz unitária Dickey-Fuller Aumentado (ADF) e o teste de Phillip-Perron (PP). A hipótese nula do teste (H0) é de que a série possui raiz unitária, ou seja, é não estacionária. Os resultados indicam que todas as variáveis são estacionárias a $5 \%$ de significância estatística quando em primeira diferença e que as variáveis não são estacionárias quando mensuradas em nível.

Com o propósito de confirmar os testes apresentados no ADF, foi realizado o teste PP, o qual possuía mesma hipótese nula do ADF. Assim, a análise dos

\footnotetext{
${ }^{5}$ Nome meramente ilustrativo apenas abreviações para facilitar os procedimentos no software.
} 
valores corrobora de um modo geral, as conclusões oriundas do ADF, ou seja, as variáveis são estacionárias a $5 \%$ de significância estatística quando em primeira diferença. Como todas as séries são estacionárias em primeira diferença, e o modelo a ser utilizado será o VAR, cabe destacar que não foram encontradas relações de co-integração. Após a análise da estacionaridade das séries, a Tabela 4 revela o número de lags ótimo, ou seja, quantas defasagens ajustam melhor o modelo.

\section{Tabela 4 - Teste de número ótimo de defasagens modelo}

\begin{tabular}{lrrrrrr}
\hline Lag & LogL & LR & FPE & AIC & SC & HQ \\
\hline 0 & $-2674,14$ & NA & 152764,4 & 23,28816 & 23,34795 & 23,31228 \\
1 & $-2587,85$ & 168,8305 & 82905,12 & 22,67693 & $22.97590^{*}$ & $22.79753^{*}$ \\
2 & $-2569,99$ & 34,3205 & 81586,46 & 22,66077 & 23,1989 & 22,87784 \\
3 & $-2541,29$ & 54,14765 & 73082,43 & 22,55037 & 23,32767 & 22,86392 \\
4 & $-2523,22$ & 33,46526 & $71822.83^{*}$ & $22.53239^{*}$ & 23,54886 & 22,94241 \\
5 & $-2512,64$ & 19,24448 & 75355,25 & 22,57944 & 23,83508 & 23,08594 \\
6 & $-2501,47$ & 19,89805 & 78703,65 & 22,6215 & 24,11632 & 23,22448 \\
7 & $-2489,86$ & 20,29828 & 81923,13 & 22,65965 & 24,39364 & 23,3591 \\
8 & $-2476,6$ & 22,71594 & 84114,64 & 22,68347 & 24,65663 & 23,4794 \\
9 & $-2460,6$ & $26.84382^{*}$ & 84396,52 & 22,68351 & 24,89584 & 23,57592 \\
\hline
\end{tabular}

Fonte: Elaborada pelos autores

Os testes apresentados na Tabela 4 indicam que o número ótimo de lags que ajustam o modelo seria de 1,4 ou 9. Entretanto a utilização de 4 lags se mostrou mais ajustada, pois pela indicação de um numero maior de testes ( indicados pelo *). Desse modo, o próximo passo é analisar a robustez do modelo aplicando alguns testes.

\subsection{Testes de robustez}

Com o propósito de confirmar se o modelo foi bem especificado é importante realizar alguns testes como: autocorrelação residual, normalidade, estabilidade. A Tabela 5 revela o teste de autocorrelação a partir dos 4lags anteriormente apontados.

Tabela 5-Teste autocorrelação modelo

\begin{tabular}{lcc}
\hline Lags & LM-Stat & Prob \\
\hline 1 & 18,78796 & 0,2798 \\
2 & 19,96229 & 0,2219 \\
3 & 14,65447 & 0,5501 \\
4 & 22,57958 & 0,1254 \\
\hline
\end{tabular}

Fonte: Elaborada pelos autores

A Tabela 5 revela que não há evidência para rejeição da hipótese nula, de inexistência de autocorrelação serial. Assim, o próximo passo é analisar a um teste de normalidade dos resíduos, e ele se mostrou estável. Finalmente um último teste foi aplicado para verificar a estabilidade do modelo VAR que pode ser observado na Figura 2. 
Figura 2 - Teste de estabilidade do VAR.

Inverse Roots of AR Characteristic Polynomial

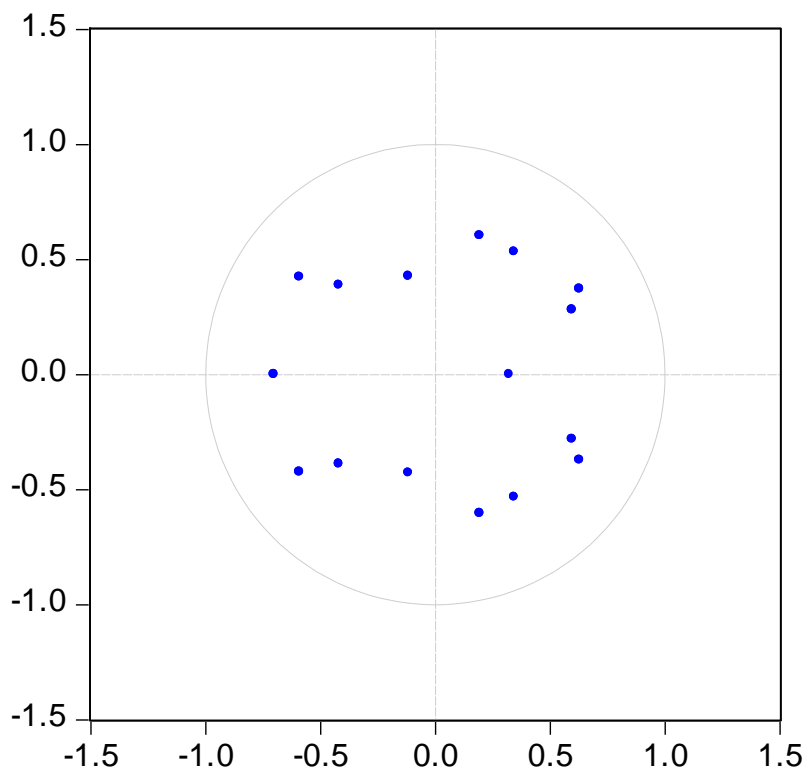

Fonte: Elaborada pelos autores.

O resultado do teste de estabilidade apresentado na Figura 1 revela que o modelo é estável. Desse modo, podemos concluir que o modelo é robusto. Outros testes de robustez também foram realizados e nenhum apresentou resultados que comprometam significativamente o modelo. Após realizar os testes de robustez 0 próximo tópico analisa as funções de impulso resposta com o propósito de verificar quais são os sinais e determinantes da arrobado boi gordo no período de 1995 até 2014.

\section{ANÁLISE DO IMPULSO RESPOSTA DO BOI GORDO}

A análise da função de impulso resposta, Figura 3 , revela importantes relações entre a arroba do boi gordo com as demais variáveis do modelo. A lógica do gráfico é a seguinte: quando ocorre um impulso positivo em cada uma dessas variáveis explicativas a linha azul nos mostra como o preço da arroba do boi gordo responde a esse impulso.

Podemos observar que a arroba, responde significativamente e positivamente ao seu próprio impulso possuindo uma clara tendência de autoregressividade, ou seja, os preços da arroba hoje são fortemente influenciados por eles mesmos, uma possível explicação está na característica intrínseca da atividade pecuária, por mais que existam fatores externos que influenciam o preço do boi gordo existe certa independência dos preços em sua trajetória, pois as mudanças na atividade são lentas, considerando que o tempo de maturação de um boi gordo para o abate é de três até cinco anos. Outra explicação advém da própria estrutura dos modelos VAR que acabam dando um peso maior na própria variável 
em relação às demais. De outro lado, um ponto relevante diz respeito ao fato da explicação da arroba pela própria arroba ir declinando com o passar do tempo.

Figura 3 - Resposta do preço da arroba do boi gordo a um choque em: Exportações, Rendimento e quantitativo de Abate de vacas em valores defasados.

Response to Cholesky One S.D. Innovations \pm 2 S.E.

Response of DARROBA to DEXPORT

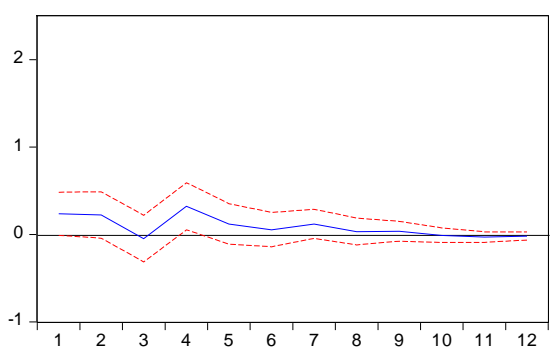

Response of DARROBA to DABATE

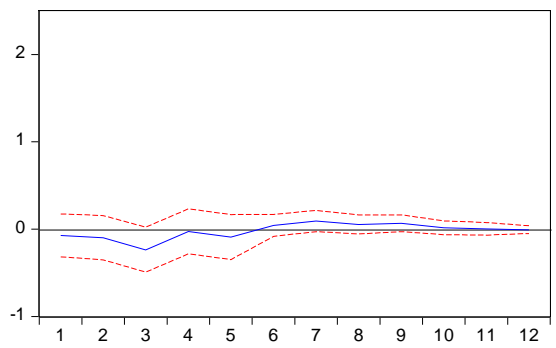

Fonte: Elaborado pelos autores
Response of DARROBA to DREND

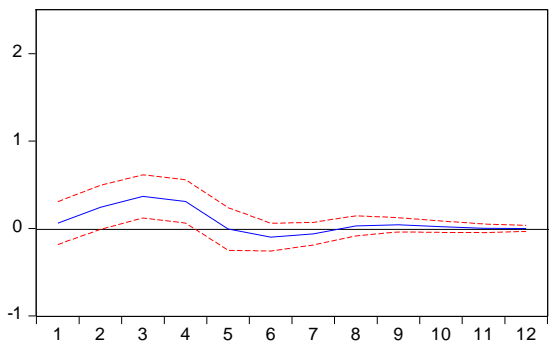

Response of DARROBA to DARROBA

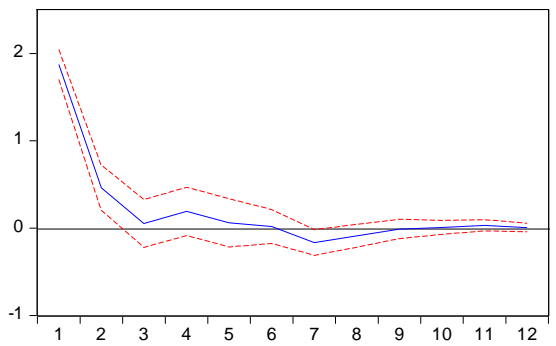

Também pode ser observado na figura 03 que o preço da arroba do boi gordo responde positivamente aos impulsos nas exportações, indicando que o setor externo tem impacto na trajetória deste preço. O impacto da elevação do rendimento real dos trabalhadores é positivo no preço da arroba do boi gordo, demonstrando que o aumento da massa salarial pressiona esses preços. Já a resposta do preço da arroba do boi gordo em relação a uma elevação no abate de vacas possui uma alternância entre, no primeiro momento, negativa e, no segundo, positiva. Esse fato pode ser explicado pela hipótese deste trabalho de que no primeiro momento quando o abate de vacas se eleva, a oferta de carne se expande e os preços tendem a cair, entretanto, no segundo momento, como essas vacas foram abatidas e consequentemente deixaram de ser matrizes, não gerando assim, novos bezerros, o tamanho de rebanho tende a diminuir (mesmo que na margem), logo, ocorre uma redução na oferta de carne, explicando assim, o resultado positivo, quando passados alguns períodos.

\section{CONSIDERAÇÕES FINAIS}

O mercado da carne é de suma importância para a economia brasileira, gerando emprego, renda e abastecendo boa parte do mercado interno brasileiro de 
consumo. Compreender a dinâmica das relações entre as variáveis selecionadas e o preço da arroba do boi gordo é de suma importância para tomada de decisão das autoridades públicas, dos agentes privados e dos consumidores em geral.

O objetivo desse trabalho foi o de analisar como os rendimentos reais dos trabalhadores, as exportações e o abate de vacas interferem no preço da arroba do boi gordo no Brasil no período de 1995 até 2014. Para tanto, foi utilizado uma metodologia dos modelos autoregressivos VAR e estimado um modelo.

Os resultados indicam que todas as variáveis impactam a arroba do boi gordo de acordo com a lógica econômica. A análise do impulso resposta revela que a variância da própria arroba explica boa parte de suas movimentações, principalmente no curto prazo. Isso é esperado, pois as demais variáveis demandam certo tempo para conseguir influenciar a arroba do boi gordo, dada a demora do ciclo de maturação da pecuária, cria, recria e engorda.

Uma elevação dos rendimentos reais dos assalariados pressiona os preços da arroba positivamente constituindo assim uma variável de explicação importante. Da mesma forma um incremento das exportações fazem a arroba do boi gordo subir dada a influencia que o setor externo exerce na atividade.

O caso mais emblemático e aqui talvez a grande contribuição da pesquisa, diz respeito à análise do impacto da quantidade de abate de vacas defasadas em quatro anos no preço da arroba do boi gordo. O resultado demonstrado pela análise de impulso respostarevela que, no curto prazo, uma elevação do abate de vacas (que se tornariam possíveis matrizes) exerce uma pressão negativa no preço da arroba do boi gordo, já que a oferta de carne se expande, todavia, passando alguns períodos, essa tendência se reverte e a quantidade de abate de vacas defasadas afeta positivamente o preço do boi gordo. Uma explicação diz respeito ao tamanho do rebanho, pois com a elevação do abate de vacas, o número de novos bezerros e bezerras diminui e, passado um prazo de maturação, com o rebanho menor, ocorre um impacto positivo nos preços da arroba do boi gordo.

Dada à relevância do tema, outros trabalhos com outras metodologias e series de tempo devem ser adotadas para compreender melhor a problemática do mercado da carne no Brasil. Apesar da robustez do modelo adotado, é sabido que toda análise desse tipo é passível de limitações.

\section{REFERÊNCIAS}

AGRIFATTO. Análise e Decisão. 2013. Disponível em:<http://www.agrifatto.com.br/?pg=edicoes>. Acesso em 01 de abril de 2014.

ASSOCIAÇÃO BRASILEIRA DAS INDÚSTRIAS EXPORTADORAS DE CARNESABIEC. Rebanho bovino brasileiro. 2014. Disponível em:http://www.abiec.com.br/3_rebanho.asp. Acesso em 02 de abril de 2014.

BARBANCHO, A. G. Fundamentos e Possibilidades da Econometria. Rio de Janeiro: Forum Editora, 1970. p. 18-32.

BLANCHARD, O. J.; QUAH, D, The dynamic effects of aggregate demand and supply disturbances. American Economic Review, v. 79, p. 655-673. 1989.

BRANDÃO, F. S.. Tendências para o consumo da carne bovina no Brasil. Tese Doutorado. Universidade Federal do Rio Grande do Sul, Centro de Estudos e Pesquisas em Agronegócio. Programa de Pós Graduação em Agronegócios. Porto Alegre - RS. 2013. 
BRASIL. Ministério da Agricultura, Pecuária e Abastecimento. Secretaria de Política Agrícola, Instituto Interamericano de Cooperação para a Agricultura - Brasília: IICA, 2007.

BUAINAIN, A. M.; BATALHA, M. O. (Coord). Cadeia produtiva da carne bovina. Brasília: MAPA/SPA/IICA, 2007 (Série Agronegócios, V. 8).

CARVALHO, T. B.; ZEN, S. Cadeia de pecuária de corte: perspectivas de produção e consumo no Brasil. In Sociedade Brasileira de Economia, Administração e Sociologia Rural - SOBER. Campo Grande-MS, 2010.

DAMBORIARENA, L. A.; VIANA, J. G. A.. Produção de Carne Bovina do Rio Grande do Sul e o Mercado Externo: Evolução e Perspectivas com Base no Território. Revista Extensão Rural, DEAER - CCR - UFSM, Santa Maria, v.21, n.4, out./dez. 2014.

ENDERS, W. Applied Econometric Time Series, $1^{\text {a }}$ ed., John Wiley \& Sons, 1995.

GRANGER, C. W. J.; NEWBOLD, Paul.Forecasting Economic Time Series. New York : Academic Press, 1977.

GRANGER, C. W. J.; NEWBOLD, Paul.Spurious regressions in econometrics.Journal of Econometrics, Nottingham, v.2, p. 111-120, Jul. 1974.

INSTITUTO BRASILEIRO DE GEOGRAFIA E ESTATÍSTICA - IBGE. Estatística da Produção Pecuária. Março de 2014. Disponível em:http://www.ibge.gov.br/home/estatistica/indicadores/agropecuaria/producaoagrop ecuaria/abate-leite-couro-ovos_201304_publ_completa.pdf. Acessoem 04 de abril de 2014.

LIVESTOCK AND POULTRY: World Markets and Trade - United States Department of Agriculture - USDA - Novembro de 2013. Disponível em: http://apps.fas.usda.gov/psdonline/circulars/livestock_poultry.pdf.

MINISTÉRIO DA AGRICULTURA. Mercado Interno de Carne. Disponível em http://www.agricultura.gov.br/animal/mercado-interno. Acesso em 04 de abril de 2014.

MORETTIN, P. A.; TOLOI, Clélia Maria de Castro. Modelos para Previsão de Séries Temporais. In: $13^{\circ}$ Colóquio Brasileiro de Matemática. Rio de Janeiro: [s.n.], 1981.

NELSON, C. R. Applied Time Series Analysis. San Francisco: Holden-Day, 1973.

REFENES, A. N. et al. Financial Modelling using Neural Networks. London: [s.n.]. Department of Computer Sciences, University College London, 1993. p. 1 - 31.

SACHS, J. A volta do espectro de Malthus. Scientific American Brasil edição 77 Outubro $2008 . \quad$ Disponível em: http://www2.uol.com.br/sciam/artigos/falta_mundial_de_alimentos_foi_prevista_por_ malthus_em_1798.html. Acesso em 11/03/2014. 
SIMS, C., Are forecasting models usable for policy analysis? Federal Reserve Bank of Minneapolis Quarterly Review, Winter, p. 1-16. 1986.

SIMS, C. Macroeconomics and reality, Econometrica, v.48, 1980.

SOUZA, R. C. Modelos Estruturais para Previsão de Séries Temporais: Abordagens Clássica e Bayesiana. In: $17^{\circ}$ Colóquio Brasileiro de Matemática. Rio de Janeiro, 1989.

WHEELWRIGHT, S. C.; MAKRIDAKIS, S. Forecasting Methods for Management. 4th edition.New York: John Wiley \& Sons Inc, 1985. 